\title{
PROCESO DE CONFIGURACIÓN DE UN DESTINO TURÍSTICO Y EFECTOS DE LA POLÍTICA TURÍSTICA EN LA REGIÓN DE MURCIA ${ }^{1}$
}

\author{
Ginesa Martínez del Vas \\ Universidad Católica de Murcia
}

\section{RESUMEN}

Este trabajo tiene como objetivo presentar y profundizar en el proceso de configuración de la Región de Murcia como destino turístico mediante el análisis de su política turística. Para dicho análisis se han tenido en cuenta, principalmente, los siguientes factores: la situación del departamento de turismo en la administración regional, la planificación estratégica y las acciones desarrolladas en la política turística regional. Todo este proceso se materializa en una periodización en las distintas fases de la evolución de dicha política.

Palabras clave: Análisis de Políticas, turismo, política turística, Región de Murcia, fases de política turística, destino turístico regional.

The shaping process of a tourist destination and the effects of tourism policy in the Region of Murcia

\section{ABSTRACT}

The aim of this research work is to present and delve into the process of shaping the Region of Murcia as a tourist destination, through the analysis of its tourism policy. For this analysis, the following factors have been mainly taken into account: the placement of the

Recibido: 23 de marzo de 2016

Devuelto para su revisión: 30 de junio de 2016

Aceptado: 20 de octubre de 2016

Facultad de Ciencias Jurídicas y de la Empresa. Universidad Católica de Murcia. Campus de Los Jerónimos. 30107 Guadalupe MURCIA (España).E-mail: gmvas@ucam.edu

1 El presente artículo recoge algunos de los aspectos tratados en la tesis doctoral de la autora sobre "La Planificación estratégica como instrumento de la política turística. Estudio aplicado a la Región de Murcia", defendida en el Instituto Universitario de Investigaciones Turísticas de la Universidad de Alicante, el 17 julio de 2014 y dirigida Dr. J. Fernando Vera Rebollo. 
tourism department within the regional government, the strategic planning and the efforts performed in regional tourism policy. This process materializes through the policy's different phases of evolution.

Keywords: Political Analysis, Tourism, Tourism Policies, Murcia Region, Phases of Toursim Policies, Local and Regional Tourism Destination.

\section{CONSIDERACIONES PREVIAS}

El turismo es una actividad productiva que va asociada al territorio y que produce el desarrollo de diversas actividades económicas (Vera, López Palomeque, Marchena y Antón, 2011). Estas actividades se traducen en un largo proceso de incursión en el espacio, que ha ocasionado, en algunos casos, cambios cualitativos y cuantitativos de interés productivo $\mathrm{y}$, en otros, ha modificado negativamente el escenario y las propiedades que fortalecían su interés y que, en sus inicios fue el impulso para la definición de la estructura productiva. Esta modificación responde a configuraciones diversas, delimitadas por tres tipos de factores: espaciales, ambientales y socioeconómicos y políticos (Vera et al., 2011).

La investigación en turismo dirige parte de su interés a analizar el poder de transformación que éste posee y las consecuencias que tiene dentro del territorio. La necesidad de transformarse rápidamente ante nuevas circunstancias, endógenas o exógenas, muestran la vulnerabilidad de las mencionadas estructuras productivas. A ello hay que añadir el escenario económico vivido en el nuevo siglo, sujeto a un cambio sustancial, efecto de dos situaciones contrapuestas: una primera fase de rápido crecimiento, marcada por cambios estructurales significativos y, una segunda, de importante regresión económica. Un marco coyuntural en dos vertientes distintas, que expone procesos de transformación y cambios significativos en el desarrollo de las actividades económicas del turismo. En definitiva, la transformación del territorio ha marcado el valor que la actividad turística ha tenido desde las dinámicas de creación y su contribución al desarrollo de las economías locales. La reconversión de los destinos turísticos en esta década se convierte en discurso permanente ante la necesidad de proteger los recursos territoriales turísticos de situaciones de agotamiento, que aportan inseguridad a las inversiones y al crecimiento de la propia estructura productiva.

Para los destinos turísticos de incorporación reciente a los mercados, el esfuerzo es ingente: la ausencia de un reconocimiento del territorio como espacio turístico, la competitividad entre los destinos, la inestabilidad de los mercados en los últimos años, la carencia de estructuras de gestión debidamente organizadas, la no definición de políticas turísticas acordes con las necesidades de la demanda y con las circunstancias del territorio, la economía y la propia dinámica sociocultural, etc., hacen que los objetivos propuestos por la gestión pública tarden o no lleguen a cumplirse totalmente.

En este marco, el estudio de la política turística centra la atención de la investigación, al presentarse como el instrumento que influye en los factores de desarrollo del turismo regional como escenario sobre el que actuar. La necesidad de este análisis viene dada, prin- 
cipalmente, por la idea de que las decisiones de las instituciones públicas influyen sobre los escenarios y marcan parte de la vocación turística del destino. Como eje de este proceso se propone un análisis de la evolución de la política turística dividida en fases. Estas fases se han delimitado principalmente considerando los dos instrumentos más relevantes para la ordenación en la política turística regional. El primero lo constituyen los instrumentos organizativos, que han sufrido importantes cambios, consecuencia del desarrollo político y económico de la región. Un mapa administrativo salpicado por la modificación constante de ubicación, denominación y por la reorganización departamental de la administración pública en materia de turismo es el efecto fundamental. Desde 1982 hasta el año 2013, en que finaliza este estudio, el departamento de turismo ha cambiado hasta en diez ocasiones. A ello, se le añade otro de los instrumentos, los planes estratégicos, de gran interés en la configuración de un destino y en el desarrollo de sus políticas turísticas. Ante este marco, se configura la investigación que se expone, siguiendo la estructura expuesta por Velasco (2004) en su estudio de la política turística española.

\section{Cuadro 1}

\section{PLANES ESTRATÉGICOS DE TURISMO DE LA REGIÓN DE MURCIA}

\begin{tabular}{|c|c|c|c|}
\hline Nombre del Plan & Periodo & Entidad responsable & Elaboración \\
\hline $\begin{array}{l}\text { Plan de Desarrollo del Turismo de } \\
\text { la Región de Murcia }\end{array}$ & 1996-1999 & $\begin{array}{l}\text { Confederación Regional de } \\
\text { Organizaciones Empresariales } \\
\text { de Murcia. CROEM. } \\
\text { Consejería de Industria, } \\
\text { Trabajo y Turismo }\end{array}$ & $\begin{array}{l}\text { Consultur } \\
\text { Consultoría turística } \\
\text { S.A. }\end{array}$ \\
\hline $\begin{array}{l}\text { Diagnóstico Turístico de la Región } \\
\text { de Murcia }\end{array}$ & $2001(*)$ & $\begin{array}{l}\text { Consejería de Turismo y } \\
\text { Cultura } \\
\text { Dirección General de } \\
\text { Infraestructuras }\end{array}$ & $\begin{array}{l}\text { Consultur } \\
\text { Consultoría turística } \\
\text { S.A. }\end{array}$ \\
\hline $\begin{array}{l}\text { Documento Base para las } \\
\text { Directrices de Desarrollo Turístico } \\
\text { Sostenible de la Región de Murcia }\end{array}$ & $2002(*)$ & $\begin{array}{l}\text { Consejería de Turismo y } \\
\text { Ordenación del Territorio } \\
\text { Dirección General de } \\
\text { Infraestructuras }\end{array}$ & $\begin{array}{l}\text { Consultur } \\
\text { Consultoría turística } \\
\text { S.A. }\end{array}$ \\
\hline $\begin{array}{l}\text { Plan de Fomento del turismo de la } \\
\text { Región de Murcia }\end{array}$ & $2002-2006$ & $\begin{array}{l}\text { Consejería de Turismo y } \\
\text { Cultura } \\
\text { Dirección General de } \\
\text { Promoción }\end{array}$ & Elaboración propia \\
\hline $\begin{array}{l}\text { Plan Director del Turismo de la } \\
\text { Región de Murcia }\end{array}$ & 2006-2012 & $\begin{array}{l}\text { Consejería de Turismo, } \\
\text { Comercio y Consumo }\end{array}$ & Emurtel S.A. \\
\hline $\begin{array}{l}\text { Estrategia de Innovación para el } \\
\text { sector empresarial turístico }\end{array}$ & $2010(*)$ & $\begin{array}{l}\text { Instituto de Fomento de la } \\
\text { Región de Murcia-INFO } \\
\text { Consejería de Cultura y } \\
\text { Turismo }\end{array}$ & $\begin{array}{l}\text { Grupo Taso } \\
\text { Tangible Turism } \\
\text { industry Expertise }\end{array}$ \\
\hline $\begin{array}{l}\text { Estrategias de desarrollo Turístico } \\
\text { de la Región de Murcia }\end{array}$ & $2010-2015$ & $\begin{array}{l}\text { Consejería de Cultura y } \\
\text { Turismo }\end{array}$ & $\begin{array}{l}\text { Tangible Turism } \\
\text { industry Expertise }\end{array}$ \\
\hline
\end{tabular}

(*) Fecha reflejada en el documento. Elaboración Propia. 


\section{LA DIVERSIDAD DE ESPACIOS TURISTICOS EN LA REGIÓN DE MUR- CIA. EL PROCESO DE CONFIGURACIÓN DE UN DESTINO EN EL CON- TEXTO REGIONAL}

Para el estudio del proceso de configuración de un destino turístico en el marco regional se han considerado los cambios en los procesos de gestión de la política turística a esta escala, así como la configuración y el desarrollo de sus instrumentos. Es por ello, que se han analizado, prioritariamente, los cambios de consejería que alberga el departamento de turismo, la puesta en marcha de planes estratégicos que regían las decisiones en materia turística, los propios hechos turísticos y la situación de la actividad económica y social de la Región de Murcia. Con todo ello, se ha configurado un proceso por fases de la evolución de la política turística regional.

De este modo, se puede establecer una división en cinco fases de desarrollo turístico, que a continuación se detallan: $1^{a}$. Fase previa a 1982; $2^{a}$. Fase inicial 1982-1994; $3^{a}$. Fase de cooperación 1995-2001; 4 ${ }^{a}$. Fase de impulso 2002-2007, y; 5a . Fase de restructuración 2008-2013.

\section{Cuadro 2}

\section{FASES DEL DESARROLLO DEL TURISMO DE LA REGIÓN DE MURCIA}

\begin{tabular}{|c|c|c|c|}
\hline Fases & Periodos & Organización administrativa & Planes \\
\hline 1. Fase previa & Antes 1982 & Dependencia Estatal & $\begin{array}{l}\text { Periodo sin Planes específicos en } \\
\text { materia de turismo }\end{array}$ \\
\hline 2. Fase inicial & 1982-1994 & $\begin{array}{l}\text { Consejería de Industria, Tecnolo- } \\
\text { gía, Comercio y Turismo } \\
\text { Consejería de Industria, Comercio } \\
\text { y Turismo } \\
\text { Consejería de Cultura, Educación y } \\
\text { Turismo }\end{array}$ & $\begin{array}{l}\text { Periodo sin Planes específicos en } \\
\text { materia de turismo }\end{array}$ \\
\hline $\begin{array}{l}\text { 3. Fase de } \\
\text { cooperación }\end{array}$ & 1995-2001 & $\begin{array}{l}\text { Consejería de Industria, Trabajo y } \\
\text { Turismo. } \\
\text { Consejería de Industria, Comercio, } \\
\text { Turismo y Nuevas Tecnologías. } \\
\text { Consejería de Turismo y Cultura } \\
\end{array}$ & $\begin{array}{l}\text { Plan de Desarrollo Turístico de la } \\
\text { Región de Murcia 1996-1999 }\end{array}$ \\
\hline \multirow[t]{2}{*}{$\begin{array}{l}\text { 4. Fase de } \\
\text { impulso }\end{array}$} & 2002-2007 & $\begin{array}{l}\text { Consejería de Turismo y Ordena- } \\
\text { ción del Territorio }\end{array}$ & $\begin{array}{l}\text { Plan de Fomento del Turismo } \\
\text { (2002-2006) }\end{array}$ \\
\hline & & $\begin{array}{l}\text { Consejería de Turismo, Comercio y } \\
\text { Consumo } \\
\text { Consejería de Turismo y Consumo }\end{array}$ & $\begin{array}{l}\text { Plan Director de Turismo de la } \\
\text { Región de Murcia 2006-2012 }\end{array}$ \\
\hline $\begin{array}{l}\text { 5. Fase de } \\
\text { restructuración }\end{array}$ & 2008-2013 & Consejería de Cultura y Turismo & $\begin{array}{l}\text { Estrategias de desarrollo turístico de } \\
\text { la Región de Murcia 2010-2015 }\end{array}$ \\
\hline
\end{tabular}

Elaboración propia.

Seguidamente se expone el desarrollo de cada una de las citadas fases, justificando sus limitaciones temporales y exponiendo los hechos más relevantes. 


\subsection{Fase previa a 1982}

La fase previa está definida por el desarrollo de la actividad turística más significativa de la Región de Murcia, que comenzó en torno a la laguna del Mar Menor. Se observan unas características geográficas propicias para que dicha actividad adquiera interés en esta área territorial. Sin repetir las características paisajísticas del entorno de la laguna del Mar Menor, sí es importante indicar que uno de los elementos que propició el interés de los visitantes eran las virtudes terapéuticas de sus aguas (debido a sus altas tasas de salinidad), lo que ha originado, a su vez, el desarrollo de salinas, que, en la actualidad, siguen produciendo importante cantidad de sal. En este marco, es lógico pensar que el primer desarrollo turístico estuviera ligado precisamente al turismo de salud, que buscaba las propiedades terapéuticas de esas aguas.

No obstante, emergieron iniciativas de desarrollo en torno al turismo, a diferencia de otros municipios costeros, que venían principalmente de la mano del sector empresarial y, no tanto, de la administración pública. Esto supuso que, de alguna manera, las acciones y decisiones llevadas a cabo en el territorio por parte de los propietarios de los terrenos adquirieran mayor peso en la toma de decisiones. Es en este marco cuando se habla del "Mito del Mar Menor" (Andrés, 1998: 20), para definir el proceso de urbanización de La Manga del Menor.

Siguiendo el planteamiento el "Mito del Mar Menor" queda configurada la "venta del sol y playa, en base a la posición estratégica de nuestro litoral”. Así, por iniciativa provincial, se creó una Comisión para emitir un informe sobre el futuro turístico de la zona de La Manga del Mar Menor, un documento realizado para la Comisión de Técnicos de Información y Turismo de la Presidencia del Gobierno. Documento que expresa las grandes perspectivas turísticas del territorio, pero sin considerar la fragilidad de su entorno.

En un entorno natural privilegiado y en el contexto del despegue del turismo de sol y playa, Tomás Maestre, un empresario local, inicia, en 1961, un proyecto urbanístico ideado por el arquitecto Bonet Castellano y apoyado por los Ayuntamientos de San Javier ${ }^{2}$ y Cartagena. Así, en 1963 una sociedad particular, acogiéndose a la Ley de Centros y Zonas de Interés Turístico Nacional, decidió poner en explotación La Manga con vistas al turismo internacional. El desarrollo que se lleva a cabo (Mateo, 1996), desde una perspectiva analítica, tanto en sus formas de ocupación del espacio, como en su dimensión funcional y territorial, se identifica en los dos modelos que exponen Vera y López (2011). El primero de ellos, el que se desarrolla en estructuras urbanas preexistentes, se desenvuelve principalmente en la zona del Mar Menor y presenta una actitud de "contagio" ante las acciones llevadas a cabo en La Manga. Es el turismo que genera crecimientos ex novo, como resultado de operaciones inmobiliarias destinadas a un turismo de segunda residencia, como en caso de La Manga, y al amparo de la Ley. A pesar del objetivo que contempla esta ley en su artículo primero "la ordenación turística del territorio nacional” en ningún momento se establecía el cómo se debería orientar territorialmente el espacio sobre que el se iba a desarrollar la actividad turística. Únicamente se limitaba a regular lo que deberían

2 El Boletín Oficial de la provincia de Murcia hizo público el 15 de junio de 1962 un anuncio del Ayuntamiento de San Javier donde indicaba que se había aprobado el 29 de mayo un plan de ordenación y urbanización de los terrenos de La Manga, que había sido diseñado por Tomás Maestre Aznar (Andrés, 1998). 
de cumplir aquellos promotores que se sujetaban esta Ley: beneficios de hasta el $50 \%$ en impuestos y bonificaciones, preferencia para obtención de créditos y derechos de uso de los bienes de dominio público (Monero, 2007).

La implantación de la actividad turística en el territorio de La Manga no contaba con las herramientas normativas de planificación necesarias que garantizaran un desarrollo sostenible de la actividad turística, desde un punto de vista estratégico y urbanístico. Dos hechos hicieron que se rompieran los proyectos iniciales de Maestre: la crisis del petróleo y el fallecimiento de Franco. Esto supuso un cambio en la configuración económica del país y una transformación de la planificación urbanística, motivada por la falta de una normativa urbanística en un contexto de transición estatal a autonómico. Comenzó, entonces, una etapa de proyectos individuales, anarquía constructiva y proyectos inconexos (Morales, 2013).

Los promotores del desarrollo aportaron un modelo definido por el incremento de viviendas de segunda residencia, que atrajera un número ilimitado de residentes regionales y de otras comunidades autónomas, apostando más por un crecimiento cuantitativo que cualitativo. Esto aportó una baja competitividad y una estacionalidad excesivamente marcada, que como se verá más adelante, representa un excesivo desgaste del territorio. El espectacular desarrollo de ocupación del territorio en La Manga llegó a su extremo y lo virginal del espacio ha hecho que su desarrollo estructural esté caracterizado por una masificación cada vez mayor que ha cuestionado en gran medida la gestión de los recursos existentes. Andrés (1998: 21), respecto a estos hechos indicaba que "Las prisas, los intereses soterrados, la mutación de las necesidades, la inadecuación de la oferta a la demanda han precipitado la obsolescencia de aquel producto turístico que hoy reclama una urgente y poco viable transformación-reconversión, en busca de un entorno de calidad".

La descompensación del desarrollo turístico regional respecto del resto del litoral español siempre ha sido una constante. Los años 70 marcarán el comienzo de la actividad turística, dibujando el modelo turístico del litoral de la Región de Murcia. El desarrollo de la oferta hotelera que hoy conocemos se define principalmente en estos años, que dejó de crecer, para dar entrada en los ochenta y noventa al modelo turístico que conocemos hoy con la construcción de miles de viviendas de segunda residencia de playa. Este aluvión constructivo se vinculó con un deseo precipitado de entrar en el mercado especulativo de este tipo de vivienda (Serrano, 2003). De hecho, desde mediados de los noventa la construcción de viviendas ha sido la verdadera actividad económica en La Manga, siendo unos años que se podrían definir como de desmedida urbanización (Espejo, 2011). Este hecho motivó el desarrollo de acciones que se alejaban de una ordenación respetuosa, dejando un territorio desequilibrado por su excesiva densidad de construcción, la baja calidad de las aguas del Mar Menor, la presión que sufre el entorno natural y rural por la acción del turismo, a la que se le suma la baja rentabilidad y productividad del territorio en la actualidad. La estructura empresarial en los años sesenta en la Región de Murcia la dibuja la oferta de plazas en establecimientos turísticos, así en el año 1969 en la región existían 3.819 plazas en hoteles, 1.286 en apartamentos turísticos y 720 en camping. Aumentado en 1980 a 11.638 plazas, 5.021 plazas en apartamentos turísticos estos últimos concentrados en la zona de costa y 1902 plazas en campings. 


\subsection{Fase inicial 1982-1994}

A principios de los años ochenta el dibujo territorial del turismo regional está prácticamente configurado. Los nuevos espacios vacacionales de La Manga han completado su desarrollo más agresivo y, en este caso, han apostado por un modelo de turismo interior (regional y nacional) basado en alojamiento de viviendas y apartamentos, que son los municipios denominados por Vera y López (2001) como “turismo-residenciales”. Junto a estos espacios, existen los urbanos tradicionales costeros del Mar Menor y la costa sur de la región, con los municipios de Mazarrón y Águilas. Estos, a pesar de representar un modelo más tradicional en torno al turismo residencial de proximidad, merecen ser mencionados. Los centros urbanos regionales más importantes van adquiriendo protagonismo debido, en gran medida, a su propio carácter centralizado y por la posición de sus recursos, que aunque no son relevantes en su singularidad, adquieren una gran importancia observados en conjunto.

Esta fase inicial se desarrolló de forma paralela al proceso de la política turística estatal, en lo que Ivars (2003) denominada política neoliberal, que termina con la culminación del proceso de transferencia de competencias a las CC.AA en el año 1989. Este proceso llevó consigo cambios de gran importancia en materia de presupuestos, reorganización administrativa, privatización de empresas públicas, el ingreso en la Comunidad Europea, conflictos de competencias, etc. que son importantes de considerar en el inicio del desarrollo de las políticas regionales. La Comunidad Autónoma de la Región de Murcia tiene las competencias en materia de turismo desde su Estatuto de Autonomía, aprobado por la Ley Orgánica 4/1982, de 9 de junio, estableciendo como propias de éstas "la promoción y ordenación del turismo en su ámbito territorial”. A partir de esta fecha son muchos los hechos que han acontecido en torno al desarrollo del turismo regional. Por ello, se marca como inicio de una nueva etapa para el turismo regional, donde se atesora el firme propósito de posicionarse como destino turístico del arco mediterráneo. Participando de las regiones que apuestan por el turismo como estrategia de diversificación productiva, que minimice la excesiva especialización agrícola o el declive industrial tal y como sucede en otros destinos, como Galicia, Cantabria, Navarra, Asturias, etc. (Marchena y Santos, 1997).

Durante los años ochenta el desarrollo de la oferta turística se caracterizaba principalmente por empresas de pequeñas dimensiones que, como en el caso de la capital murciana, presentaban cierto atractivo por la calidad de sus instalaciones y el trato con los clientes. La concentración de la actividad turística se encontraba en torno al Mar Menor, que continuaba definiendo un modelo turístico residencial. El inicio de este periodo, al igual que en el resto de CC.AA, estuvo marcado por un periodo legislativo de ordenación y regulación de la oferta turística. De igual modo, comenzaron iniciativas que motivaron el impulso turístico. Esto es, se desarrollaron actuaciones de gran relevancia, principalmente a finales de los ochenta y principios de los noventa, como la construcción de una oferta de alojamiento público en el interior de la Región, con el Camping de la Puerta, 1989 (Moratalla), el Hotel del Cenajo, en 1991, y en 1992, ampliando espacio geográfico para potenciar el turismo rural, se inaugura el camping La Rafa (Bullas). Todo ello, fue desarrollado y gestionado por la empresa pública Sociedad para la Promoción Turística 
del Noroeste, $S . A .^{3}$ (SODETUR), constituida el 16 de marzo de 1989, y que tenía como objetivo la implantación y el desarrollo de actividades turísticas en la zona del Noroeste murciano. Estas iniciativas pretendían diversificar la oferta turística y ampliar el escenario turístico excesivamente concentrado en el litoral y apostar por nuevos productos turísticos.

Comenzando los años noventa, e influenciados por la crisis del turismo español que se venía arrastrando desde finales de los ochenta, la Región sigue sin ofrecer una estrategia de interés para el desarrollo de la actividad turística. Las asociaciones turísticas van adquiriendo más peso y exigen iniciativas en materia de turismo al gobierno. De este modo, la promoción y comercialización de los productos estrella de la región (sol y playa y producto cultural) serán las estrategias a seguir por parte de la administración. De forma paralela, el Estado puso en marcha el I Plan de Competitividad del Turismo Español (1992-1996), donde dejó claramente manifestada la necesidad de cualificar los destinos consolidados para poder recuperar la competitividad. En este contexto, y a través del Programa de apoyo a la conservación de la excelencia turística en entornos naturales y urbanos, se concedió a la Región de Murcia el Plan de Excelencia de La Manga (1993-1995). Esta intervención se llevó a cabo con la coordinación de la Secretaría General de Turismo, a través del Plan Marco de Competitividad, los Ayuntamientos de Cartagena y San Javier, la Comunidad Autónoma y con las principales organizaciones empresariales del entorno. Este tipo de iniciativas, que venían tuteladas desde el Estado, ayudaban a direccionar las políticas regionales en materia de turismo y establecer una estructura organizativa de gestión efectiva. De forma paralela, surgieron intervenciones empresariales de relevancia, como por ejemplo, la adquisición para la gestión de la Cadena hotelera Hyatt, de La Manga Club, y del Hotel Príncipe Felipe, único hotel de 5 estrellas, que pasará a denominarse a partir del año 1993 Hotel Príncipe Felipe-Hyatt Regency La Manga. Andrés (1998) lo define como “un modelo a imitar” por la calidad de los equipamientos, la ausencia de impactos negativos en el entorno, la interesante oferta de empleo e incluso el prestigio a nivel internacional que ha alcanzado y que, a pesar de contar con el mismo déficit de infraestructuras que el resto del litoral murciano, no se encuentra afectado por la estacionalidad.

Mientras se desarrolla el turismo rural en el interior, se observa que, a pesar de los esfuerzos a mediados de los años noventa, la Región de Murcia ya constituía una excepción en el panorama turístico mediterráneo español, claramente manifestada en su escasa especialización y desarrollo.

Las líneas de intervención de la política turística regional, a finales de esta fase, estaban orientadas hacia dos direcciones: la primera a la cualificación, diversificación y mejora del producto sol y playa (comercializando Costa Cálida), teniendo como lugar de desarrollo prioritario La Manga de Mar Menor; y la segunda al impulso de nuevos productos en nuevas áreas de actuación en torno al turismo rural, centrado principalmente en la Comarca del Noroeste (Vera y Amor, 1996). La primera de estas intervenciones estaba apoyada

3 La Empresa Pública Regional Sociedad para la Promoción Turística del Noroeste S.A. tiene por objeto la promoción y el desarrollo turístico del Noroeste de la Región de Murcia y, en especial, del término municipal de Moratalla y sus zonas limítrofes a través de la explotación, gestión, cesión, arriendo, subarriendo, adjudicación o cualquier otra figura jurídica aplicable, de las instalaciones de todo tipo relacionadas con el turismo. 
por el ya mencionado Plan de Excelencia de La Manga del Menor, pero también se debe añadir el impulso que le dio la Mancomunidad de Servicios del Mar Menor y las actuaciones del Ministerio de Obras Públicas y la propia Comunidad Autónoma que, bajo un convenio, establecía una inversión de 40 millones de pesetas al año para el equipamiento de las playas. Respecto de la segunda intervención, orientada al desarrollo turístico de los municipios del interior, cabe decir que se implantó más como una necesidad, debido a la desaceleración económica de los procesos rurales y a la despoblación de los espacios. Estas estrategias vienen apoyadas por el programa LEADER.

Las Mancomunidades de Municipios comienzan a constituirse a principios de la década de los noventa (Mancomunidad de Municipios del Valle de Ricote 1990, Mancomunidad de Servicios turísticos del Mar Menor 1992, Mancomunidad de Servicios Turísticos de Sierra Espuña 2001, Mancomunidad de Servicios Turísticos del Noroeste 2003, Mancomunidad de Servicios Turísticos del Nordeste 2003), usando fórmulas de gestión turística local que se adaptaran a las circunstancias específicas del territorio y que tuvieran aspectos comunes a la realidad turística y socioeconómica.

\section{Cuadro 3}

\section{EVOLUCIÓN DE LA OFERTA EN ESTABLECIMIENTOS TURÍSTICOS Y NÚMERO DE TURISTAS EN LA REGIÓN DE MURCIA DE 1982 A 1995}

\begin{tabular}{|c|c|c|c|c|c|c|c|c|}
\hline Años & Hoteleros & Apartamentos & Campings & Rural & $\begin{array}{c}\text { Total de la } \\
\text { oferta }\end{array}$ & $\begin{array}{c}\text { Tasa de } \\
\text { variación }\end{array}$ & $\begin{array}{c}\mathrm{N}^{\mathbf{0}} \text { de } \\
\text { Viajeros } \\
(*)\end{array}$ & $\begin{array}{c}\text { Tasa de } \\
\text { variación }\end{array}$ \\
\hline 1982 & 11.989 & 4.178 & 3.382 & & 19.549 & $1,62 \%$ & n.d. & \\
\hline 1983 & 12.206 & 4.616 & 8.036 & & 24.858 & $27,16 \%$ & n.d. & \\
\hline 1984 & 12.236 & 5.040 & 8.036 & & 25.312 & $1,83 \%$ & n.d. & \\
\hline 1985 & 11.652 & 5.984 & 8.036 & & 25.672 & $1,42 \%$ & n.d. & \\
\hline 1986 & 11.568 & 6.315 & 8.036 & & 25.919 & $0,96 \%$ & n.d. & \\
\hline 1987 & 11.693 & 6.475 & 8.696 & & 26.864 & $3,65 \%$ & 330.502 & \\
\hline 1988 & 11.886 & 7.334 & 8.696 & & 27.916 & $3,92 \%$ & 332.193 & $0.51 \%$ \\
\hline 1989 & 12.242 & 8.509 & 8.696 & & 29.447 & $5,48 \%$ & 413.224 & $24.39 \%$ \\
\hline 1990 & 12.754 & 9.755 & 11.092 & & 33.601 & $14,11 \%$ & 450.982 & $9.14 \%$ \\
\hline 1991 & 13.417 & 8.962 & 11.829 & & 34.208 & $1,81 \%$ & 489.691 & $8.58 \%$ \\
\hline 1992 & 13.550 & 8.828 & 12.179 & & 34.557 & $1,02 \%$ & 436.231 & $-10.92 \%$ \\
\hline 1993 & 14.013 & 8.803 & 12.722 & 111 & 35.649 & $3,16 \%$ & 441.581 & $1.23 \%$ \\
\hline 1994 & 14.360 & 9.379 & 12.911 & 165 & 36.815 & $3,27 \%$ & 432.439 & $-2.07 \%$ \\
\hline 1995 & 14.617 & 8.714 & 13.007 & 341 & 36.679 & $-0,37 \%$ & 417.406 & $-3.48 \%$ \\
\hline
\end{tabular}

n.d: No existen datos. (*)Numero de viajeros en alojamientos reglados

Fuente. Unidad de Estadística del Instituto de Turismo de la Región de Murcia. Elaboración propia.

El final de esta fase coincide con el cambio de gobierno regional: en 1995 gana las elecciones en la Región de Murcia el Partido Popular y D. Ramón Luis Valcárcel Siso es investido nuevo Presidente. 


\subsection{Fase de cooperación 1995-2001}

La nueva administración pública, que se constituye el 30 de junio de 1995, debe, como se verá en la siguiente fase, enfrentarse a dos aspectos de gran interés: por un lado, a los problemas tradicionales, que giraban, principalmente, alrededor de la preocupación por el desarrollo inmediato de las infraestructuras básicas que acercaran los mercados a la Región de Murcia. Y, por otro, al desarrollo y definición de un verdadero modelo turístico regional, que permitiera definir acciones que aportaran transformación e innovación a la región como destino turístico. Tras las elecciones de 1995, y con el cambio político que supone la entrada en el gobierno regional del Partido Popular y la correspondiente reestructuración de la administración pública, se propició en la política turística una profunda transformación. Esta fue orientada, precisamente, al empuje de esta actividad como elemento de interés para el desarrollo de la actividad económica regional. La estructura organizativa de la administración regional cambió de nombre, al igual que la administración Turística, que no lo había hecho desde 1987, pasando a denominarse en 1995 Consejería de Industria, Trabajo y Turismo.

El impulso del nuevo gobierno, bajo la clara intención de generar una verdadera política turística regional, presentó resultados diversos durante esta fase: el desarrollo del primer Plan Desarrollo del Turismo; la disposición de estructuras de gestión públicaprivada; la definición de la Ley de Turismo; la diversificación de la oferta turística hacia nuevos productos (rural y cultural) y se palían parte de las disfunciones en infraestructuras.

El Plan de Desarrollo Turístico de la Región de Murcia (1996-1999) será el primer plan que se lleve a cabo de estas características en la región, bajo encargo y tutela la Confederación Regional de Organizaciones Empresariales de Murcia, CROEM junto con Consejería de Industria, Trabajo y Turismo. El documento y el mismo proceso de desarrollo del Plan comenzó a aportar espacios de reflexión públicos y privados de gran valor, definiendo un diagnóstico sobre la situación del turismo regional y estableciendo vías de acción por las que dirigir las futuras acciones en materia turística.

A partir de este momento, es lógico observar que las disfunciones con las que tendrá que convivir el escaso desarrollo turístico murciano deberán ser resueltas dentro de las políticas regionales globales. Ahora es el momento de actuar de forma ordenada y bajo el paradigma de la coordinación, alejándose de actuaciones aisladas, espontáneas y ausentes de cualquier planificación. Con el objetivo de pasar a un momento de implicación de todos los agentes decisorios regionales y con la finalidad de desarrollar una verdadera gestión y promoción en materia turística se produce un cambio en el modo de hacer las cosas y aparece un verdadero interés por parte de algunos agentes del sector por colaborar en las nuevas estrategias nacidas del Plan de Desarrollo del Turismo de la Región de Murcia. Andrés (1998) lo define como un "intento de ruptura total con la manera de hacer hasta este momento", que es manifestada a su vez en un cambio en la imagen turística comercial de la Región: la ya tradicional "Costa Calidad" pasará a denominarse "La Costa Cálida", modificación que irá acompañada de la transformación en la imagen. Esta decisión es atacada por la oposición en la Asamblea Regional y por el sector turístico en general por cambiar una imagen que ya contaba con quince años de vida.

Otro aspecto de gran interés es el surgimiento de nuevas fórmulas de gestión turística, donde el empresario murciano, junto con la administración pública y otro tipo de orga- 
nizaciones, podían administrar el producto turístico de su destino y establecer estrategias más localizadas y motivadoras en un espacio determinado. Se extrae una conclusión clara: un cambio generalizado mediante lo que define como "nueva política turística", basada en planteamientos de organización, promoción y gestión de la actividad, acordes con las necesidades del sector y la realidad del mercado. En este nuevo marco nacieron los Consorcios Turísticos Empresariales, algunos de ellos motivados por el Plan Futures II, donde se creaban estructuras que permitían escenarios de desarrollo de productos de empresas privadas con apoyo del sector público. Los objetivos de estos Consorcios Turísticos son: "la presentación de los servicios necesarios en orden a la constitución, gestión, control y promoción de los distintos turismos: náuticos; sol y playa; rural salud/termal; ciudad/ cultural; ciudad/congresos" (Andrés, 1999: 395).

La fase de cooperación estuvo marcada por la buena coyuntura del sector turístico, en la que se aprecia una consolidación de la región como destino turístico, y por una política turística que apostó por la cooperación público-privada como estrategia. Así los resultados mostraron una consolidación de la Región de Murcia como destino que iba acompañado por la "nueva forma de hacer" (Andrés, 1999). El crecimiento de la oferta fue significativo en el entorno rural gracias al florecimiento de este producto, principalmente, en la zona del noroeste, lo que motivó la implantación de una nueva marca turística, "Murcia, Tierra dentro", que identifica un nuevo escenario turístico regional. Se produjo, de este modo, un cambio significativo, con la existencia de dos marcas que delimitan la zonificación turística de la región y una clara distribución del espacio turístico.

Se identificaron, entonces, tres zonas turísticas de interés: Murcia ciudad, por su interés como capital, la zona del litoral, "Murcia, La Costa Cálida", y la zona del interior "Murcia, Tierra dentro". Bajo este paraguas, siguen aconteciendo hechos de gran relevancia para el turismo regional, que ayuda a romper la estacionalidad concentrada en el litoral y a diversificarla, con el desarrollo de un producto cultural regional de relevancia (García y Alburquerque, 2003). Así, a través del programa operativo de los fondos europeos FEDER (Fondos Europeo de Desarrollo Regional), se implementaron dos acciones de gran interés para la promoción del turismo de cultural: una, el proyecto "Lorca Taller del Tiempo", bajo el Consorcio para el Desarrollo Cultural y Turístico de Lorca4; la otra motivada por el privilegio de celebrar el "Año Santo in perpetuum", cada siete años en torno a la Santísima y Vera Cruz de Caravaca, constituyéndose, además, la sociedad “Caravaca Jubilar”, para el desarrollo del producto cultural-religioso. Cartagena será el tercer destino cultural de la región; el municipio consiguió la declaración de zona piloto para la aplicación de un Plan de Dinamización Turística, que intentó, junto con el programa URBAN, paliar los problemas urbanos y sociales consecuencia de su proceso industrial y su plurifuncionalidad, lo que requirió una transformación integral de la ciudad y la rehabilitación de su casco histórico (Andrés, 1999b). De igual modo, se crea La Asociación de Consorcios Turísticos de la Región de Murcia (Murcia Data).

Se produjo una nueva reestructuración en 1999 y el departamento de turismo se ubica en la denominada Consejería de Industria, Comercio, Turismo y Nuevas Tecnologías, encargada de las acciones de la política institucional turística y el INFO, que como años

4 Se crea para su gestión la sociedad instrumental denominada Lorcatur. 
atrás, mediante la empresa pública Región de Murcia Turística, S.A., gestiona la promoción turística. Durante este año siguen existiendo dos factores que hicieron que la actividad turística siguiera sin consolidarse en la región. El primero de ellos, se debió principalmente a las no solucionadas infraestructuras básicas de comunicación; como ejemplo, podemos citar la no concluida autovía que comunica Murcia con Albacete y que, por lo tanto, afectó a la conexión directa con Madrid del litoral murciano. También se encuentra sin terminar la Autopista de Cartagena-Alicante, una vía fundamental para poder unir la costa murciana con el mediterráneo y fundamentalmente con el litoral del Mar Menor, conexión estratégica para poder desarrollar una vía de acceso al aeropuerto del Altet de Alicante.

Por otro lado, la vía de comunicación entre Cartagena-Vera seguía siendo una proyecto, por lo que la zona del litoral sur continuaba paralizada ante un posible desarrollo turístico. La red nacional de Alta Velocidad no terminaba de proyectarse en dirección Murcia, por lo que las infraestructuras ferroviales seguían obsoletas (red inadecuada para la comunicación con Alicante y Madrid e inexistencia de comunicación con Andalucía) En esta misma situación quedaba el proyecto del aeropuerto para la región, (Andrés, 2000; Espejo y Ponce, 1999).

El segundo de los factores se debe a la consolidación de un modelo turístico orientado principalmente a la segunda residencia, especialmente en La Manga, lo que ocasionó el estancamiento en el desarrollo de una verdadera oferta turística. La estacionalidad, la necesidad de realizar esfuerzos en los servicios públicos, la paralización de actividades durante largos períodos, la ausencia de una actuación real para la ordenación de los espacios todavía libres, los cambios de la demanda que busca espacios menos agresivos con el medioambiente, etc. originó que el espacio turístico más importante de la región fuera perdiendo interés por parte de los turistas y de los posibles inversores turísticos. Por ello, al definirse la región dentro de un modelo, principalmente, orientado al turista de segunda residencia se quiere hacer eco de que dicho modelo presentó un escaso impacto en la economía murciana. En este período se constituyen dos nuevos consorcios turísticos: el Consorcio Agencia para la promoción del Noroeste y La Manga Consorcio.

Las elecciones autonómicas de 1999 son favorables nuevamente al Partido Popular murciano, ahora la Consejería de Economía y Hacienda mediante la Dirección General de Presupuesto, Programación y Fondos Europeos lleva a cabo el Plan Estratégico de desarrollo de la Región de Murcia 2000-2006, en el que el turismo aparece, nuevamente, como estrategia económica clave y se repite el intento de que la actividad turística termine de definirse como una actividad económica de relevancia para la región.

Con este panorama de visible crecimiento, ordenación y estrategia comienza el nuevo siglo. Con él, la Secretaría General del Estado estrena nuevo plan, el PICTE (2000-2006) que, mediante su programa de calidad en destinos, sigue impulsando los Planes de Excelencia Turística en destinos tradicionales maduros y Planes de Dinamización Turística ${ }^{5}$ para el desarrollo de destinos turísticos emergentes con fuerte potencial de atracción turística. La

5 En la Región de Murcia en total se desarrollaron 2 planes de Excelencia (La Manga, 1993 y Mar Menor, 2005), 10 Plan de Dinamización (Cartagena, 1998; Mazarrón, 1998; Águilas, 1998; Caravaca de la Cruz, 2000; Valle de Ricote, 2000; Murcia-El Valle, 2001; Sierra Espuña, 2002; Noroeste de la Región de Murcia, 2003; Nordeste-Altiplano, 2004 y Sierra Minera, 2005), 3 Planes de Dinamización de Producto (Lorca, 2006; Desfiladero de Almadenes, 2007 y Medina Nogalte 2008) y Plan de Competitividad Turística de La Manga del Menor “Turismo Náutico" 2010. 
administración regional en materia de turismo vuelve a cambiar de denominación, llamándose ahora Consejería de Turismo y Cultura. Se conceden nuevos fondos estructurales a la Región, con el LEADER + (de 2000 a 2006), que seguirá apoyando al desarrollo del turismo rural. Dichos fondos están distribuidos por prácticamente todo el territorio rural de la región.

La administración pública regional, en un nuevo intento de retomar el turismo como una actividad económica para la Región de Murcia, creó en el 2000 la Consejería de Turismo y Cultura ${ }^{6}$, cuyo nuevo Consejero habla de la necesidad de "cambiar el modelo estructural y económico de la Región” (Andrés, 2001). Con este cambio estructural la nueva Consejería asume todas las competencias en materia de turismo, que antes estaban distribuidas entre el INFO y en una Dirección general. Ahora, sin embargo, se encuentra con una Consejería que cuenta por primera vez con dos Direcciones Generales en materia de turismo: la Dirección General de Promoción Turística y la Dirección General de Infraestructuras Turísticas. Esta nueva acción puso de manifiesto el interés de la Administración Regional, concretado en la reorganización de una actividad económica de gran interés. La recién creada Consejería puso en marcha una nueva política turística regional con un presupuesto aproximado de mil quinientos millones de pesetas, donde la partida más importante iba dirigida a la promoción, ordenación, Planes de Dinamización y la creación y apoyo de consorcios turísticos. A esto se debe añadir la presentación de una nueva imagen promocional de Murcia, "Murcia Turística". Esta marca asumió una gran variedad de productos y recursos, que tiene el objetivo de promocionar a la Región en su conjunto, como un destino turístico "multiproducto". En este impulso se incorpora un nuevo equipo de directores generales que establecen su política turística atendiendo al Plan Estratégico de Desarrollo regional, que planteaba entre sus objetivos "cambiar la estructura económica de la Región mediante el desarrollo cualificado y sostenible del sector turístico, en el marco legal de la Ley de Turismo 11/97”. Se establecieron, además, estrategias de gestión para sus políticas turísticas. Con el fin de ser fieles a dicho objetivo, la administración regional de turismo activó el Plan de Fomento del Turismo 2002-2006, que articuló los instrumentos de gestión de la política turística regional sobre la base de cuatro subplanes: Plan de Formación, Plan de Información, Plan de Promoción y Plan de Calidad. Este plan constituyó un documento de gran sencillez tanto en su estructura, como en su ejecución; fue elaborado y difundido por la administración con el apoyo del sector.

La fase que ahora se trata termina con la solución de importantes disfuncionalidades referidas a las infraestructuras. Se finaliza la autovía Murcia-Albacete y la autopista AP-7 Cartagena-Alicante; la autovía del Noroeste hasta Caravaca y la autovía de Lorca-Águilas, que consigue comunicar el interior regional con el litoral. Para completar los trazados de comunicación del litoral murciano queda pendiente el proyecto de la Autopista CartagenaVera. Estas actuaciones son relevantes por el hecho de que la región adquiere una posición competitiva y el espacio regional comienza a definirse como un todo. La accesibilidad y la reducción de las distancias hizo que los municipios se sintieran abiertos ante la llegada de visitantes y que se dieran cuenta de que en ellos también se podían desarrollar interesantes productos turísticos, al amparo de recursos o actividades de interés, que sólo necesitaban

6 Decreto 30/2000, de 5 de mayo, que reorganiza la Administración Regional. BORM, 6 de mayo, 2000, p. 104. Decreto 14/2001, de 9 de febrero, que establece la estructura orgánica de la Consejería de Turismo y Cultura. 
ser estructurados. Este hecho, junto con la política turística de la gestión global del territorio regional como destino turístico, marca lo que podríamos definir como "la oportunidad turística”, que tiende a estructuras similares, al ya conocido "Mito del Mar Menor". Sin embargo, en este caso existía un interés por el desarrollo de políticas turísticas locales al margen de la vocación turística y de las propias oportunidades del territorio. Este hecho desencadenará la carrera por ser destino turístico, un esfuerzo que se basará más en la inversión que en el beneficio.

Por último, mencionar que el modelo turístico del litoral seguía con la tendencia de un turismo residencial vacacional y no hay ningún indicio de que este aspecto fuera a modificarse. La Manga sigue condicionada por su estacionalidad, principalmente entre el 10 de julio al 25 de agosto y su reducido número de plazas hoteleras, tan sólo 10 hoteles con un total 3.752 plazas, condicionante, que, junto al haber convertido dicho espacio en un lugar de desarrollo urbanístico, hacía que continuara sin definirse como destino turístico En este sentido, el inicio de una etapa económica basada en la construcción urbanística, que afectaba de forma directa al litoral, acentuaba, aún más, el desarrollo de este modelo (Espejo, 2001). Por su parte, el turismo rural adquirió una posición de relevancia, con un fuerte crecimiento progresivo repartido por todo el territorio regional, aunque con fuerte concentración en la comarca del noroeste. Este tipo de turismo surgió con gran fuerza, gracias a los programas de la Unión Europea, pero presentaba algunos aspectos que marcarán su posterior decadencia, principalmente en la ausencia de unos objetivos concretos de desarrollo, que paliaran las deficiencias productivas del territorio (Andrés, 2000b).

Respecto de los datos de la oferta y demanda, se observa para la fase de análisis que los datos de la tasa de variación anual siguen siendo positivos. El incremento de las plazas se concentra considerablemente en los alojamientos rurales, como consecuencia de los programas europeos. El aumento del número de turistas que visita la región contempla datos más inestables, aunque al final de la serie dichos datos sigue siendo positivos.

\section{Cuadro 4 \\ EVOLUCIÓN DE LA OFERTA EN ESTABLECIMIENTOS TURÍSTICOS Y NÚMERO DE TURISTAS EN LA REGIÓN DE MURCIA DE 1996 A 2001}

\begin{tabular}{ccccccccc}
\hline Años & Hoteles & Apartamentos & Campings & Rural & $\begin{array}{c}\text { Total } \\
\text { de la } \\
\text { oferta }\end{array}$ & $\begin{array}{c}\text { Tasa de } \\
\text { variación }\end{array}$ & $\begin{array}{c}\mathbf{N}^{\mathbf{d}} \text { de } \\
\text { Turistas } \\
(*)\end{array}$ & $\begin{array}{c}\text { Tasa de } \\
\text { variación }\end{array}$ \\
\hline 1996 & 14.630 & 8.570 & 13.637 & 472 & 37.309 & $1,72 \%$ & 423.876 & $1,55 \%$ \\
\hline 1997 & 14.772 & 8.739 & 13.916 & 591 & 38.018 & $1,90 \%$ & 401.212 & $-5,35 \%$ \\
\hline 1998 & 14.991 & 8.965 & 13.916 & 887 & 38.759 & $1,95 \%$ & 380.912 & $-5,06 \%$ \\
\hline 1999 & 15.170 & 8.529 & 13.916 & 1.179 & 38.794 & $0,09 \%$ & 414.446 & $8,80 \%$ \\
\hline 2000 & 15.372 & 8.424 & 14.699 & 1.490 & 39.985 & $3,07 \%$ & 439.999 & $6,17 \%$ \\
\hline 2001 & 15.458 & 8.186 & 15.122 & 1.846 & 40.612 & $1,57 \%$ & 480.753 & $9,26 \%$ \\
\hline
\end{tabular}

(*) Número de viajeros en alojamientos reglados

Fuente. Unidad de Estadística del Instituto de Turismo de la Región de Murcia. Elaboración propia. 


\subsection{Fase de impulso 2002-2007}

Esta fase, sin duda, es la más importante, y viene determinada por el lugar de relevancia que tiene el departamento de turismo y la política turística en la estrategia económica regional. Dicho departamento pasa a pertenecer a la Consejería de Turismo y Ordenación del Territorio, continuando con la misma estructura en dos Direcciones Generales (Infraestructuras de Turismo y de Promoción Turística), con sus correspondientes competencias. La determinación de unir Turismo con Ordenación del Territorio es determinante para fijar el inicio de una nueva etapa en el proceso de la gestión pública del turismo regional, donde la intervención en la planificación del territorio adquiere un peso relevante. Los documentos de diagnóstico turístico que se habían puesto sobre la mesa ya hablan de definición turística con vocación exclusivamente turística y de que debían ser tenidos en cuenta en la planificación territorial de la Región. Previo a estos documentos, e incluso de forma paralela, a causa del largo proceso de elaboración, se fue definiendo, dentro de la iniciativa comunitaria Interreg II-C “Modelos Territoriales Sostenibles en Espacios Litorales del Mediterráneo”, un documento que servía de instrumento para la ordenación territorial de litoral regional. Este documento lo genera la Consejería de Turismo y Ordenación del Territorio en la Dirección General de Ordenación del Territorio y Costas con el nombre: Directrices y Plan de Ordenación Territorial del Litoral de la Región de Murcia ${ }^{7}$ (a partir de ahora DPOTL). Surge, entonces, una de las herramientas más importantes de planificación territorial de la Región de Murcia. Ordena el desarrollo del litoral y adquiere una clara intención de convertirlo en un territorio con vocación turística. De este modo, la política turística regional con la política territorial supone un acercamiento firme con el objetivo de marcar los nuevos escenarios turísticos. El documento indica tres "actuaciones estratégicas". La primera de ellas va orientada a la construcción del Aeropuerto Internacional de la Región de Murcia, por su necesidad estratégica para la accesibilidad del turismo extranjero a todo el espacio litoral. Por ello se considera Actuación de Interés Regional ${ }^{8}$. La segunda, orientada al desarrollo de oferta turística, bajo la configuración de un nuevo proceso productivo desde los parámetros de un modelo de desarrollo sostenible (DPOTL, 59):

1. Deben ser actuaciones emblemáticas dirigidas por el sector público.

2. Las actuaciones deben ser integrales y respetuosas con el medio ambiente.

7 Decreto $n^{\circ} 1 / 2011$, de 21 de enero, de Modificación n ${ }^{\circ} 2$ de las Directrices de Ordenación Territorial del Litoral de la Región de Murcia.- Decreto 1/2007 por el que se modifica el decreto 57/2004 de aprobación de las DPOTL de la Región de Murcia. Resolución de la Dirección General de Ordenación del Territorio y Costas por la que se dictan instrucciones interpretativas del anexo V de la normativa de las DPOTL de la Región de Murcia aprobadas por Decreto 57/2004, de 18 de Junio, y de los artículos 5 y 41 de la normativa de las Directrices y Plan de Ordenación Territorial del Suelo Industrial (DPOTSI) de la Región de Murcia, aprobadas por Decreto 102/2006, de 8 de Junio (DG 783/2007).- Decreto 57/2004, de 18 de junio, por el que se aprueban las Directrices y Plan de Ordenación Territorial del Litoral (DPOTL) de la Región de Murcia.

8 Resolución del 6 de Abril de 2004, de la Secretaría General de la Consejería de Turismo y Ordenación del Territorio, por la que se dispone la publicación del Acuerdo del Consejo de Gobierno de 18 de marzo de 2004, por el que se declara como Actuación de Interés Regional, la implantación del Aeropuerto Internacional de la Región de Murcia. 
3. Deben potenciar el turismo de calidad sobre la base de una oferta hotelera importante versus la oferta residencial vacacional actualmente existente en la zona, como una oferta complementaria que posibilite la utilización y explotación de los recursos a lo largo de todo el año.

De este modo, se justifica la creación de espacios urbanísticos ${ }^{9}$ definidos como resort y de espacios turísticos residenciales abiertos con grandes infraestructuras hoteleras. El DPOTL, entonces, justificaba el desarrollo del proyecto Actuación de Interés Región de Marina de Cope ${ }^{10}$ que, previamente a la probación de la Directrices, había sido declarado por la Ley 1/2001 de 24 de abril del Suelo de la Región de Murcia"11: "La Actuación de Interés Regional de Marina de Cope cumple con los requisitos de esta ley, dado que tiene por objeto la ordenación y gestión de una zona del territorio para facilitar el desarrollo económico y por su magnitud e importancia beneficia al conjunto de la Región de Murcia en el ámbito de su economía" (DPOTL, 598). La última de las actuaciones se ordena en torno a Portmán y la Sierra Minera, que pretendía la regeneración ambiental de la Bahía de Portmán, y la restauración ambiental y paisajística de la Sierra Minera con el desarrollo urbanístico de la zona.

Al margen de los grandes proyectos turísticos previstos para la región, y volviendo a la estructura departamental del turismo, desde la Dirección de Promoción Turística, con el Plan de Fomento del Turismo (2002-2006), se llevan a cabo varias actuaciones y se definirá la base para la puesta en marcha del Centro de Cualificación Turística (CCT) regional con el desarrollo de varios cursos específicos para el sector. La definición del Plan de Calidad apoyó la constitución de la Delegación Territorial del Instituto para la Calidad turística española (ICTE), en la que se encuentran involucradas las asociaciones turísticas más relevantes de la Región. Conjuntamente, se debe englobar la política turística regional en el marco del PICTE, plan estatal, que parte de la premisa de contar con la colaboración y coordinación de las distintas CC.AA y asociaciones turísticas, estableciendo como eje principal de desarrollo de la competitividad la calidad de los productos de los destinos y del sector turístico.

En la Feria Internacional de Turismo (FITUR) del año 2002, se presentó una nueva imagen de "Murcia Turística", que según el Gobierno Regional era necesaria por la creciente importancia de otros productos turísticos (García, García, y Aniorte, 2003). El producto turístico cultural va adquiriendo una posición cada vez más importante, que se exterioriza a través de los productos Lorca Taller del Tiempo, Cartagena Puerto de Cultu-

9 “El Modelo de Desarrollo Urbanístico que se planteará para este nuevo espacio se encuentra a mitad de camino entre la fórmula del resort autónomo y el espacio residencial turístico abierto. Esta solución mixta permitiría adaptar los nuevos desarrollos al marco espacial del entorno mediterráneo en el que tiene lugar, fijar población estable en este espacio de nueva creación y contribuir a la rentabilidad de las inversiones iniciales. Las grandes infraestructuras hoteleras se compaginarán así con importantes equipamientos deportivos, comerciales, sanitarios, educativos y de ocio así como con espacios residenciales integrados en la trama urbana" (DOPTL, 59).

10 Resolución del 28 de julio de 2004 de la Vicesecretaría General de la Consejería de Medio Ambiente y Ordenación del Territorio, por la que se dispone la publicación del Acuerdo del Consejo de Gobierno del 23 de julio de 2004, por el que se declara como Actuación de Interés Regional, la Marina de Cope.

11 Que regula las Actuaciones de Interés Regional como instrumentos de ordenación del territorio de carácter excepcional. 
ras y Caravaca Jubilar, ésta última preparándose para el año Jubilar 2003. A esto se debe añadir la exposición Huellas, que fue inaugurada el 23 de enero de 2002. Se definió, por consiguiente, lo que sería la nueva estrategia turística, basada en la diversificación de productos turísticos y el creciente auge del turismo cultural, con un total de 596.640 visitantes (García, 2003). Esta diversificación de productos se aprecia, también, en la constitución de nuevos consorcios turísticos, como el Consorcio Centro Turístico de Talasoterapia de San Pedro del Pinatar, una iniciativa público-privada que intentaba poner en marcha nuevos productos orientados, en este caso, al turismo de salud.

El Partido Popular volvió a obtener la mayoría absoluta en las elecciones del año 2003. La política turística continuó trabajando sobre las mismas líneas de actuación, obedeciendo las propuestas del Plan de Fomento: apoyar el incremento de la actividad promocional, formativa y sensibilizando al sector empresarial con el apoyo del ICTE territorial para aumentar el número de adhesiones y certificaciones. Desde la Dirección General de Infraestructuras se siguió la política de apoyo de Planes de Dinamización, incorporando para este año el del Noroeste y el del Consorcio Vía Verde del Noroeste. Las estrategias continuaban desarrollándose en pos del aumento y cualificación de los productos turísticos puestos en valor; por ello se continúan consolidando dichos productos y surgiendo estrategias para el aumento de la competitividad de los destinos. Caravaca, con su año jubilar, adquirió un posición de relevancia y se convirtió en elemento de gran proyección del turismo regional, debido, principalmente, a su calado en toda la cristiandad. Sin embargo, a pesar del gran esfuerzo por la transformación integral del conjunto urbano y de la planificación turística, Caravaca no alcanzó los objetivos previstos, por diversas causas, especialmente por su falta de compromiso local (Andrés y Espejo, 2006).

Se llevó a cabo una nueva reorganización de la estructura departamental en turismo, por Decreto del Consejo de Gobierno ${ }^{12}$, creándose la Consejería de Turismo, Comercio y Consumo, que asumió las competencias en materia de turismo. Las competencias de Ordenación del Territorio pasarán a otra Consejería de nueva creación, la Consejería de Medio Ambiente y Ordenación del Territorio. Esta ruptura se debe, en gran medida, a que habían sido definidas las Actuaciones de Interés Regional por la planificación territorial y turística, por lo que la segregación de las mismas estaba justificada. A pesar de los cambios departamentales la política implementada es la misma de años anteriores, aunque se observa como dato reseñable la creación de siete consorcios turísticos: Murcia, Cruce de Caminos, Medina Nogalte, Sierra Minera, Desfiladero de Almadenes, Mazarrón, Valle del Ricote y Marina de Cope. Este es un buen momento de la política turística ${ }^{13}$, la Región de Murcia se sitúa entre los gobiernos que se han incorporado más tarde al desarrollo turístico, pero que han reforzado sus estratégicas de fomento del turismo como motor de desarrollo económico, especialmente en el medio rural (Exceltur, 2004)

12 Decreto $^{\circ}$ 60/2004, de 28 de junio, de reorganización de la Administración Regional. BORM N ${ }^{\circ} 148$, (29/06/2004).

13 Exceltur realiza un estudio en el 2003 que revela que Murcia es la Comunidad Autónoma donde los empresarios tienen una mejor opinión sobre sus líneas de política turística, con un amplio consenso sobre la adecuada dirección de las iniciativas públicas que afectan al turismo. Encuesta de Clima Turístico Empresarial de Exceltur; donde se establecen la siguientes cuestiones: promoción turística, inversión en infraestructuras básicas, inversión en oferta complementaria (de ocio y/o de diferenciación), protección ambiental, seguridad ciudadana, fiscalidad, normativas propias del sector y ordenación urbanística. 
El programa de renovación de las ciudades de Lorca, Cartagena y Caravaca implicó una revalorización de la cultura como recurso turístico, que significó para los municipios el desarrollo del turismo cultural. En el caso de Cartagena, es una realidad en el momento en el que dicha renovación tuvo un componente social y patrimonial en la implicación y aceptación de la comunidad local, que acompañó a dicho proceso. Éste culminará, en una primera fase, con la inauguración en el año 2008 del Teatro Romano de Cartagena, determinando un conjunto urbano en el que se conjugan actividades turísticas polivalentes. Su gestión permitió una acción sostenible sobre el patrimonio, con rehabilitación de edificios que pueden tener un uso turístico, ampliando así su oferta, tanto cuantitativa como cualitativamente (Salvá, 1998). Estas acciones buscaban, en todo momento, lo que Mínguez (2013) determina como un equilibrio que garantice el estado de conservación de los bienes, la calidad de las visitas, adaptadas a las características de la demanda, y la sostenibilidad económica.

Será en esta fase cuando la acción del turismo suponga una mayor transformación del territorio desde los años setenta y ochenta, con la definición de La Manga. Se dibuja un nuevo mapa turístico para la Región de Murcia con una gran numero de proyectos orientados a un "nuevo modelo de urbanización”, que, lejos de ser innovador, aporta cierto escepticismo en la sociedad regional. Este nuevo modelo vino inspirado por diversas causas, entre las que se podría citar los cambios productivos del suelo agrícola, que, ante los problemas a los que se enfrenta y en la búsqueda de una alternativa, se pretende redefinir dentro del proceso urbanizador de, principalmente, las zonas periurbanas de costa (Vera, 2006). El modelo sobre el que se asienta es el de las inquietudes de la demanda extranjera que buscan una interrelación entre la residencia y el campo de golf (Andrés, 2004). Un modelo conocido como "resort" dibuja un nuevo mapa del turismo regional, que si bien ha sufrido importantes desequilibrios debido a la crisis, sí responde a transformaciones de consideración, que en ningún momento fueron tenidas en cuenta en la planificación territorial y turística regional.

Uno de los aspectos que más llama la atención es la rapidez con que se desarrolló todo el proceso, la gran dimensión espacial (abarcó a un importante número de municipios) y el interés por abandonar sectores productivos de gran valor para volcarse en el desarrollo desmesurado de la segunda residencia (Serrano, 2007). Durante esta fase y ante los cambios producidos, apoyados por la administración, el sector turístico de la Región de Murcia adquirió la calificación de región "residencial”, entendido como el carácter marcadamente inmobiliario de las relaciones entre el destino y el visitante (Torres, 2003).

Sin duda, este periodo es uno de lo más relevantes de la historia del turismo regional por la toma de decisiones y por la coyuntura económica que se vive durante esos años. En cualquier caso, se pueden definir tres categorías de factores que pueden enmarcar este periodo: las circunstancias coyunturales en las que se encuentra inmersa la región desde un punto de vista económico, las potencialidades derivadas del estado de las infraestructuras, que son capaces de satisfacer las exigencias de la propia actividad económica relacionada con el turismo y, por último, el potencial efecto que puede derivarse de los posicionamientos de la gestión política que asume el propio Plan Director de Turismo de la Región de Murcia, que expresa, desde su aprobación, las acciones y los retos que plantean la necesidad de definir un nuevo modelo turístico regional ante la nueva demanda (Andrés, 2007). 
Ante lo acontecido posteriormente, se puede indicar, indudablemente, que esta fase fue la más importante y la de mayor dinamismo de la política turística regional, por el despliegue que la administración hace de todos sus instrumentos. Uno de esos instrumentos es el número de consorcios que se constituyen, los denominados por Cebrián (2005) "pactos locales," instrumentos que serán utilizados por parte de la administración pública local y regional para desarrollar procesos de reestructuración y puesta en valor de territorios con cierta vocación turística. Un hecho, sin embargo, difícil de sustentar económica y territorialmente.

Las consecuencias del esfuerzo por parte de los distintos agentes se aprecia, principalmente, en el despliegue de una gran diversidad de productos, principalmente concentrados por una oferta de plazas de alojamiento rural, que sigue en alza, y por el crecimiento del turismo residencial, que, por su magnitud (se observa un crecimiento notable en el número de ciudadanos europeos residenciales) indica que la Región se incorpora al desarrollo turístico residencial con la misma intensidad que sus comunidades vecinas (Ródenas, 2005). De este modo, a partir del 2003, será tenido en cuenta en los estudios de demanda.

En el siguiente cuadro se analizan los datos de la oferta y demanda turística respecto a los años que representen la fase de análisis. Todos los datos aportan variaciones de crecimiento positivas en cada una de las variables analizadas. Para esta serie se incluyen los datos referentes al turismo de segunda residencia, debido al peso que adquiere este tipo de turismo en la región por el incremento de viviendas relacionadas con el turismo extranjero.

\section{Cuadro 5 \\ EVOLUCIÓN DE LA OFERTA EN ESTABLECIMIENTOS TURÍSTICOS Y NÚMERO DE TURISTAS EN LA REGIÓN DE MURCIA DE 2002 A 2007}

\begin{tabular}{lccccccccc}
\hline Años & Hoteles & Apt. & Campings & Rural & $\begin{array}{c}\text { Total de } \\
\text { la oferta }\end{array}$ & $\begin{array}{c}\text { Tasa de } \\
\text { variación }\end{array}$ & $\begin{array}{c}\mathbf{N}^{\mathbf{0}} \text { de } \\
\text { Turistas } \\
\left({ }^{*}\right)\end{array}$ & $\begin{array}{c}\text { Tasa de } \\
\text { variación }\end{array}$ & $\begin{array}{c}\mathbf{N}^{\mathbf{0}} \text { de } \\
\text { Turistas } \\
\left({ }^{* *}\right)\end{array}$ \\
\hline 2002 & 15.956 & 8.224 & 15.377 & 2.014 & 41.571 & $2,36 \%$ & 561.049 & $16,70 \%$ & \\
\hline 2003 & 16.685 & 8.326 & 15.467 & 2.281 & 42.759 & $2,86 \%$ & 612.706 & $9,21 \%$ & 3.556 .907 \\
\hline 2004 & 16.931 & 8.564 & 15.467 & 2.548 & 43.510 & $1,76 \%$ & 689.268 & $12,50 \%$ & 3.779 .120 \\
\hline 2005 & 17.810 & 8.304 & 15.467 & 2.753 & 44.334 & $1,89 \%$ & 758.252 & $10,01 \%$ & 4.212 .316 \\
\hline 2006 & 18.931 & 8.362 & 15.467 & 2.898 & 45.658 & $2,99 \%$ & 798.283 & $5,28 \%$ & 4.529 .756 \\
\hline 2007 & 19.571 & 8.696 & 15.467 & 3.004 & 46.738 & $2,37 \%$ & 808.987 & $1,34 \%$ & 4.957 .691 \\
\hline
\end{tabular}

(*) Numero de viajeros en alojamientos reglados.

$\left(^{* *}\right)$ Estimación del número de turistas llegados a la Región de Murcia a Establecimientos Hoteleros, Apartamentos turísticos, Camping, vivienda propia / alquilada, alojamiento rural y otros. A partir del año 2003 se tienen en cuenta los datos de la segunda residencia.

Fuente. Unidad de Estadística del Instituto de Turismo de la Región de Murcia. Elaboración propia.

\subsection{Fase de restructuración 2008-2013}

Sin duda, esta fase se caracteriza por el declive de la situación de la economía española en general y la regional en particular. Esta situación mostrará la parte más débil del sector; 
la fuerte dependencia de los mercados nacionales, ahora en crisis, hacen que las cifras de demanda desciendan y los precios se vean afectados de forma negativa. Por lo tanto, se establece un periodo que se puede definir como de restructuración del tejido empresarial turístico, que se basa principalmente en el ajuste de precios, generación de productos, formas de comercialización y calidad de los servicios. Este periodo va a estar definido por la ausencia de planificación estratégica, ya que a pesar de tener documentos de referencia estos no son tenidos en cuenta en la toma de decisiones por falta de visión estratégica en el desarrollo de la política turística y porque dichos documentos no se actualizan y quedan obsoletos ante la nueva situación del entorno turístico, el estado del propio sector y los cambios de administración pública, que afectan, en gran medida, a la gestión de los instrumentos de la política turística regional y con el ello al propio desarrollo del sector.

La administración pública se vio en la necesidad de reordenarse, reduciendo en un $20 \%$ los cargos y las estructuras públicas. Uno de los afectados será el departamento de Turismo, que pasa nuevamente, como sucedió en el año 2000, a Cultura, pero en este caso será la Consejería de Cultura que, como órgano único, acoja el turismo, pasando a denominarse Consejería de Cultura y Turismo. Este hecho tuvo diversas consecuencias en la política turística regional de importante trascendencia. Entre ellas, destacamos una fuerte apuesta por la diversificación de productos, principalmente orientados a las acciones en torno a hechos culturales, y la continuación de la puesta en valor de recursos patrimoniales. De este modo, la política turística en todo el periodo estuvo caracterizada por la austeridad, que se acentúa considerablemente en los últimos años de esta fase. A pesar de esta situación, el 2008 fue el año con mayor presupuesto, en torno a los 29 millones de euros. Los primeros meses se aplicó una acción de gran repercusión: el lanzamiento de la campaña publicitaria bajo la creación de una nueva marca turística, que fue presentada en FITUR 2009 “Murcia busca su estereotipo”, envuelta en una gran polémica. La campaña tenía como objetivo en sí misma definir un nombre para Murcia. Así, se pasa de "Región de Murcia, donde vive el Sol" a "Región de Murcia: No-Typical", envuelto todo en una complicada estrategia de marketing.

Comienza, entonces, una fase de incertidumbre, que rompe con el pasado para crear una nueva estrategia de futuro, enmarcada por una nueva gestión pública del turismo. En este marco, La Manga sigue siendo el enclave más importante de la Región de Murcia, pero sigue estando en una situación de estancamiento dentro de la política turística regional debido a dos factores: el nuevo proyecto Interés Regional Marina Cope, que la dejaba al margen ante un espacio de nueva creación, y la situación de agotamiento del tradicional modelo turístico del litoral, que afectaba al litoral español y, más especialmente, al murciano, debido a la pérdida de competitividad de los modelos tradicionales y al deterioro progresivo, que afectaba a esa posición competitiva. Esta situación de deterioro deja un territorio donde los factores de competitividad (entorno físico, tecnológico, social, ambiental e institucional), para desarrollar actividades económicas generadoras de riqueza y empleo, no se han dado de forma correcta (González y Mendieta, 2009). Espejo (2011) hace referencia a los elementos o pilares que precisan una necesaria, en pleno siglo XXI, innovación para potenciar la competitividad de La Manga, destacando: sus condiciones naturales, la accesibilidad, los recursos naturales para la práctica de deportes náuticos, la oferta hotelera que ha ido mejorando y por último, se hace referen- 
cia al diseño y desarrollo del Plan de Competitividad Turística de La Manga "Estación Náutica”. Prueba del impulso que se le quiere otorgar al territorio es que, se comienza a trabajar para la concesión de dicho Plan. Así el Ministerio de Industria, Turismo y Comercio, la Consejería de Cultura y Turismo de la Región de Murcia y La Manga Consorcio, ponen en marcha el Plan de Competitividad Turística del Producto Turístico Náutico "La Manga Turismo Náutico", que tiene como objetivo reposicionar La Manga como destino turístico, potenciando el turismo náutico como principal producto diferenciador frente a otros destinos de sol y playa, y, además, tiene que contribuir a la renovación de la imagen del destino "La Manga” (Espejo, 2011). Pero este importante hecho no llegó a su fin, ya que se interrumpió su financiación por parte de la administración regional ante la grave situación económica de la administración. A ello, se le sumo, la disolución de 15 consorcios turísticos por parte de la Consejería, rompiendo así una estructura que se había creado en la fase anterior y que representaba la organización sobre la que descansaba el esfuerzo de los destinos y productos turísticos, pero que carecía de una verdadera vocación sostenible.

En términos generales, y al margen de lo expuesto anteriormente, la actividad turística en esta fase, tiene un comportamiento muy similar a la anterior, materializado en la reducción de la demanda por la crisis del turismo doméstico y la desaceleración del crecimiento de la oferta. La fuerte dependencia del turismo de segunda residencia y la estacionalidad del turismo en la zona de La Manga, la bajada de precios, el descenso de la ocupación y el empleo son comportamientos preocupantes para el sector que requieren de revisión y planificación. Igualmente, se observa cómo unos sectores que se comportan de forma diferente, como el turismo rural, es el sector más afectado, precisamente por la dependencia del turismo nacional y por el desarrollo al margen del territorio. También hay un descenso en el número de pernoctaciones en los espacios urbanos más importantes del interior.

El 2013 también estuvo salpicado por nuevos cambios departamentales. Se creó el Instituto de Turismo de la Región de Murcia y se aprobó la nueva Ley de Turismo regional. Los datos de la oferta y la demanda arrojan datos positivos en la mayoría de las series analizadas, a pesar de la situación de crisis. La resistencia del sector se aprecia claramente y la tasa de variación en el número de turistas no presenta únicamente un dato negativo. El crecimiento de la oferta sigue siendo positivo, a excepción del año 2010, que presenta datos negativos por el descenso en el número de plazas de alojamiento en el sector hotelero, camping y casas rurales, tal y como se puede apreciar en el Cuadro 6.

Como conclusión, cabe, decir que la fase de restructuración estuvo salpicada por importantes cambios en la política turística, que describen un nuevo momento de la política turística, redefiniéndose los instrumentos y generando unos acordes a la nueva situación. Surge, entonces, lo que podría definirse como "la nueva política turística regional”, basada en la austeridad presupuestaria y administrativa, aligerando el organigrama y disolución de los consorcios turísticos, la gestión de la innovación y la tecnología como eje sobre la que basar la planificación y la toma de decisiones, el estudio del mercado para la creación y promoción del producto y un entorno de colaboración publico privado más participativo. A ello, le unimos la nueva Ley de Turismo de diciembre de 2013, que pretende abrir las puertas de una nueva estructura productiva más cercana a la demanda; a lo que le suma el apoyo, principalmente, de destinos consolidados frente a la demanda, 
como es el caso de Cartagena. Toda esta gestión está tutelada, como se ha indicado anteriormente, por una nueva estructura departamental con el nombre de Instituto de Turismo de la Región de Murcia y una nueva marca "Destino Región de Murcia”.

\section{Cuadro 6 \\ EVOLUCIÓN DE LA OFERTA EN ESTABLECIMIENTOS TURÍSTICOS Y DEL NÚMERO DE TURISTAS EN LA REGIÓN DE MURCIA DE 2008 A 2013}

\begin{tabular}{cccccccccc}
\hline Año & Hoteles & Apta & Campings & Rural & $\begin{array}{c}\text { Total de } \\
\text { la oferta }\end{array}$ & $\begin{array}{c}\text { Tasa de } \\
\text { variación }\end{array}$ & $\begin{array}{c}\mathbf{N}^{\mathbf{0}} \mathbf{d e} \\
\text { viajero } \\
(*)\end{array}$ & $\begin{array}{c}\text { Tasa de } \\
\text { variación }\end{array}$ & $\begin{array}{c}\mathbf{N}^{\mathbf{0}} \mathbf{d e} \\
\text { Turistas } \\
(* *)\end{array}$ \\
\hline 2008 & 19.914 & 10.225 & 15.467 & 3.181 & 48.787 & $4,38 \%$ & 882.500 & $9,09 \%$ & 5.068 .493 \\
\hline 2009 & 20.435 & 10.064 & 15.623 & 3.367 & 49.100 & $0,64 \%$ & 925.449 & $4,87 \%$ & 4.917 .983 \\
\hline 2010 & 20.165 & 10.076 & 14.440 & 3.298 & 47.979 & $-2,28 \%$ & 1.081 .019 & $16,81 \%$ & 5.175 .087 \\
\hline 2011 & 20.404 & 10.421 & 14.743 & 3.391 & 48.959 & $2,04 \%$ & 1.167 .489 & $8,00 \%$ & 5.196 .623 \\
\hline 2012 & 20.482 & 10.834 & 14.866 & 3.377 & 49.559 & $1,23 \%$ & 1.253 .663 & $7,38 \%$ & 5.106 .137 \\
\hline 2013 & 20.671 & 11.609 & 14.866 & 3.476 & 50.622 & $2,14 \%$ & 1.296 .417 & $3,41 \%$ & 5.133 .006 \\
\hline
\end{tabular}

(*) Numero de viajeros en alojamientos reglados

(**) Estimación del número de turistas llegados a la Región de Murcia a Establecimientos Hoteleros, Apartamentos turísticos, Camping, vivienda propia / alquilada, alojamiento rural y otros. A partir del año 2003 se tienen en cuenta los datos de segunda residencia.

Fuente. Unidad de Estadística del Instituto de Turismo de la Región de Murcia. Elaboración propia

\section{CONCLUSIONES}

Las fases analizadas han mostrado la configuración del proceso del desarrollo turístico de la Región de Murcia. Se han definido de la mano de la política turística, basada en los instrumentos organizativos que definen la posición departamental del turismo en la administración pública regional, los instrumentos normativos y los referentes al desarrollo de planes estratégicos de desarrollo turístico. Así, dicho proceso se ha divido en: $1^{a}$. Fase previa a 1982; $2^{a}$. Fase inicial 1982-1994; $3^{a}$. Fase de cooperación 1995-2001; $4^{a}$. Fase de impulso 2002-2007, y; 5a . Fase de restructuración 2008-2013. Estas fases permiten tener una visión de los hitos turísticos regionales, que sirven para comprender la situación del turismo en la Región de Murcia.

De este modo, se podría indicar que anterior a 1982 es la fase en la que se ha definido el modelo turístico regional, basándose en el desarrollo del turismo del litoral como segunda residencia, con una demanda estacional, concentrada en torno al Mar Menor y con una limitada comunicación con los mercados internacionales, aspectos que siguen siendo una constante en la actualidad en la región. Durante la fase inicial comienza a configurarse un marco administrativo de ordenación y regulación, a la par que se va diversificado la oferta al amparo de los programas estatales y europeos. La política turística regional encuentra su mayor desarrollo en la fase de cooperación (1995-2001) y, posteriormente, en la fase de impulso (2002-2007). El despliegue de los instrumentos de la política turística regional en estas dos fases adquiere una posición de gran valor ocasionando una clara intención 
de hacer de la Región de Murcia un destino turístico. La diversificación de la oferta, las estrategias de promoción, la creación de estructuras de cooperación publico-privadas, el desarrollo de planes estratégicos y la cualificación de los recursos e infraestructuras coinciden en estas fases. Pero también se observan diferencias en la última fase de impulso, especialmente ocasionadas por la situación favorable de la economía regional, que comienza a apoyar la transformación productiva del territorio, mediante la construcción de desarrollos urbanísticos asociados al golf, los proyectos de interés regional y la propia creación de oferta. Esto puede reflejar una política turística con cierto carácter intervencionista. Ante este escenario, llega la fase de reestructuración (2008-2013), que viene ocasionada, precisamente, por una situación totalmente contraria, debido la crisis económica. La reducción considerable del presupuesto hace que comience una fase de incertidumbre, donde no tiene cabida la planificación turística. La política turística sin planificación clara se limita a la disolución de estructuras administrativas y al desarrollo de acciones de promoción e innovación ante las cifras negativas de la demanda por la crisis del turismo doméstico.

El análisis expuesto muestra un desarrollo turístico amenazado por varias constantes, tales como las distintas fases generadas por las variaciones tanto de la gestión pública del turismo regional, como de la política turística y los cambios de ubicación del departamento de turismo en la administración regional. Esto último ha originado escenarios de incertidumbre y renovación al no perfilarse una línea estratégica clara que ayude a definir un verdadero modelo turístico regional. Y, de hecho, esta ausencia de modelo permanece, de tal forma que en el año 2014 el Departamento de Turismo se incluyó en la Consejería de Industria, Turismo, Empresas e Innovación, volviendo a promocionar la marca ya utilizada "Costa Calidad. Región de Murcia". Posteriormente, tuvo lugar otro cambio, en el año 2015, con la creación de la Consejería de Desarrollo Económico, Turismo y Empleo.

A esto se debe sumar una inadecuada gestión de la marca turística regional, la carencia de una verdadera gestión de la política turística, que debería haberse basado en una adecuada planificación estratégica, consensuada entre los distintos agentes y cuyo objetivo fuera ordenar los instrumentos de dicha política. Además de conseguir el establecimiento de estrategias comunes entre los diferentes ámbitos regionales, que realmente coincidieran en un mismo fin, relacionado con el desarrollo turístico de la Región de Murcia. La disolución de los Consorcios Turísticos o la marcha de la administración pública de algunos de ellos, deja un panorama de incertidumbre y hace vislumbra la política llevada a cabo, basada en el desarrollo de varios frentes a escala territorial e institucional, como insostenible por el excesivo gasto que genera. Ahora la reflexión queda abierta y es necesario dibujar un nuevo escenario para la política turística regional donde no se debe olvidar el pasado para definir el futuro.

\section{BIBLIOGRAFÍA}

ANDRÉS SARASA, J.L. (1998): Turismo y Territorio en la Región de Murcia. Murcia. Instituto de Fomento de Región de Murcia.

ANDRÉS SARASA, J.L. (1998b): "Encadenamiento y mudanza en el destino turístico “Murcia, la Costa Cálida”. En La Actividad Turística Española en 1996. Edición de 1997. Madrid. Publicación Anual de la Asociación Española de Expertos Científicos en Turismo (AECIT). 
ANDRÉS SARASA, J.L. (1999): "Región de Murcia”. En BOTE GÓMEZ, V. (Dir.). La Actividad Turística Española en 1998. Madrid. Asociación Española de Expertos Científicos en Turismo (AECIT).

ANDRÉS SARASA, J.L. (1999b): «Turismo y Estrategias para la Recuperación de las ciudades históricas». Cuadernos de Turismo, n 3, pp. 7-30.

ANDRÉS SARASA, J.L. (2000): "Región de Murcia”. En VALDÉS PELÁEZ, L. (Dir.). La Actividad Turística Española en 1999. Madrid. Asociación Española de Expertos Científicos en Turismo (AECIT).

ANDRÉS SARASA, J.L. (2001): "Región de Murcia”. En VALDÉS PELÁEZ, L. (Dir.). La Actividad Turística Española en 2000. Madrid. Asociación Española de Expertos Científicos en Turismo (AECIT).

ANDRÉS SARASA, J.L. (2004): «Incertidumbres en el espacio agrícola y proceso urbanizador «resort» en la Región de Murcia», Cuadernos de Turismo, nº 14, pp. 7-65.

ANDRÉS SARASA, J.L. (2007): "El turismo". En ROMERO DÍAZ, A. (Coord.). Atlas Global de la Región de Murcia, Murcia, La Verdad, Comunidad Autónoma de la Región de Murcia, Asamblea Regional y Fundación Cajamurcia.

ANDRÉS SARASA, J.L. y ESPEJO, C. (2006): «Interacción mito religioso/producto turístico en la imagen de la ciudad: Caravaca de la Cruz (Murcia)», Cuadernos de Turismo, $\mathrm{n}^{\circ} 18$, pp. 7-61.

CEBRIÁN ABELLÁN, A. (2005): «Acción local, turismo y patrimonio en la Comunidad de Murcia», Cuadernos de Turismo, n 16, pp. 65-83.

CEBRIÁN ABELLÁN, A. (2006): «Ordenación turística y cooperación interinstitucional en la Comunidad de Murcia», Cuadernos de Turismo, n 17-18, pp. 5-22.

CONFEDERACIÓN REGIONAL DE ORGANIZACIONES EMPRESARIALES MURCIANAS (CROEM) Y CONSEJERÍA DE INDUSTRIA, TRABAJO Y TURISMO. Plan de desarrollo turístico de la Región de Murcia 1996-2000. Documento Ejecutivo. CONSEJERÍA DE TURISMO Y CULTURA DE LA REGIÓN DE MURCIA: Plan de Fomento del turismo, pp. 34. Región de Murcia.

CONSEJERÍA DE TURISMO, COMERCIO Y CONSUMO DE LA REGIÓN DE MURCIA. Plan director de turismo de la Región de Murcia 2006-2012. Dirección General de Infraestructuras Turísticas, pp.431. Región de Murcia.

CONSEJERÍA DE TURISMO Y ORDENLACIÓN DEL TERRITORIO DE LA REGIÓN DE MURCIA. Directrices y Plan de Ordenación Territorial del Litoral de la Región de Murcia D.P.O.L. (2007).

ESPEJO MARÍN, C. (2001): La Manga del Mar Menor. En VALDÉS PELÁEZ, L. (dir.). La Actividad Turística Española en 2000. Madrid. Asociación Española de Expertos Científicos en Turismo (AECIT).

ESPEJO MARÍN, C. (2011): «Innovación para la Competitividad Turística en La Manga del Mar Menor (Murcia)», Cuadernos de Turismo, n 27, pp. 321-339.

ESPEJO MARÍN, C. y PONCE SANCHEZ, M.D. (1999): «Turismo de congresos y reuniones en la ciudad de Murcia», Cuadernos de Turismo, $\mathrm{n}^{\circ} 3$, pp. 45-59.

EXCELTUR (2004): Valoración empresarial de la política turística autonómica y central durante el año 2003. Encuesta de Clima Turístico Empresarial, pp. 1-21. 
GARCÍA SÁNCHEZ, A. y ALBURQUERQUE, F.J. (2003): «El turismo cultural y el de sol y playa ¿sustitutivos o complementarios?», Cuadernos de Turismo, $\mathrm{n}^{\circ} 11, \mathrm{pp}$. 97-115.

GARCÍA SÁNCHEZ, A., GARCÍA SAURA, P.J., y ANIORTE, J.J. (2003): “Región de Murcia”. En ANTON CLAVÉ, S. (Dir.). La Actividad Turística Española en 2002. Madrid. Asociación Española de Expertos Científicos en Turismo (AECIT).

IVARS BAIDAL, J.A. (2003): Planificación turística de los espacios regionales en España. Generalitat Valenciana. Editorial Síntesis.

MARCHENA GÓMEZ, M.J. y SANTOS, E.L. (1997): «Actividad, empleo y paro turístico en las regiones españolas (1991-1995)», Investigaciones Geográficas, nº 17, pp. 37-56.

MATEO GIRONA, M.R. (1996). Proceso de configuración y planificación territorial de un espacio turístico y de ocio. La Manga del Mar Menor. Tesis Doctoral inédita. Universidad de Murcia. Departamento de Geografía. Facultad de Letras. Vols II más anexo cartográfico.

MÍNGUEZ GARCÍA, M.C. (2013): «La gestión de la oferta turística-cultural en los grandes hitos patrimoniales. El caso de Patrimonio Nacional», Boletín de la Asociación de Geógrafos Españoles, n 63 , pp. 225-248.

MORALES YAGO, F.J. (2013): «El impacto de la actividad turística sobre el paisaje de La Manga del Mar Menor (Murcia)», Estudios Geográficos, n 275, pp. 523-556.

MORENO GARRIDO, A. (2007): Historia del turismo en España en el siglo XX. Madrid. Editorial Síntesis.

RÓDENAS, J. (2005): “Turismo residencial y asentamiento de ciudadanos europeos en la Región de Murcia, aplicación de técnicas cuantitativas de investigación social". En MAZÓN MARTÍNEZ, T. y ALEDO TUR, A., Turismo Residencial y cambio social. CAM, Obra social FRAX, Alicante. Universidad de Alicante.

SALVÁ TOMÁS, P.A. (1998): «Los modelos de desarrollo turístico en el mediterráneo», Cuadernos de Turismo, $\mathrm{n}^{\circ}$ 2, pp. 7-24.

SERRANO MARTÍNEZ, J.M. (2003): «Las viviendas de segunda residencia en la sociedad del "bienestar". El caso de un país turístico: España», Cuadernos de Turismo, no 12 , pp. 53-75.

SERRANO MARTÍNEZ, J.M. (2007): «El turismo residencial en la Región de Murcia frete a los nuevos restos», Cuadernos de Turismo, nº 19, pp. 189-216.

TORRES BERNIER, E. (2003): «El turismo residenciado y sus efectos en los destinos turísticos». Estudios Turísticos, nº155-156, pp. 33-48.

VELASCO GONZÁLEZ, M. (2004): La política turística. Gobierno y Administraciones Turísticas en España (1952-2004). Valencia. Fundación Cañada Blanch y Ayuntamiento de Burriana.

VERA REBOLLO, J. F. (2006): «Agua y modelo de desarrollo turístico: La necesidad de nuevos criterios para la gestión de los recursos.», Boletín de la Asociación de Geógrafos Españoles, $\mathrm{n}^{\circ}$ 42, pp. 155-176.

VERA REBOLLO, J. F. (COORD.), LÓPEZ PALOMEQUE, F., MARCHENA GÓMEZ, M.J. y ANTON CLAVÉ, S. (2011): Análisis territorial del turismo y planificación de destinos turísticos. Valencia. Tirant Lo Blanch. 
VERA REBOLLO, J.F. y AMOR, F. (1996): “Comunidad Autónoma de la Región de Murcia”. En La actividad turística española en 1994. Madrid. Asociación Española de Expertos Científicos en Turismo (AECIT).

VERA REBOLLO, J.F. y LÓPEZ PALOMEQUE, F. (2001): "Espacios y destinos turísticos”. En GIL OLCINA, A. y GÓMEZ MENDOZA, J. (Cood.). Geografía de España, Barcelona, Ariel. 